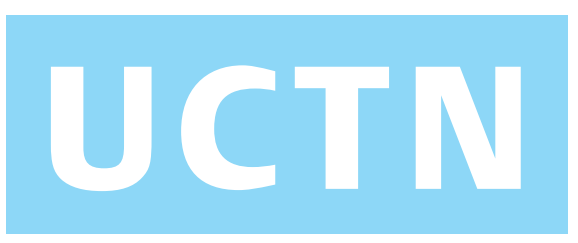

\title{
Cholecysto-pancreatitis due to Ascaris lumbricoides
}
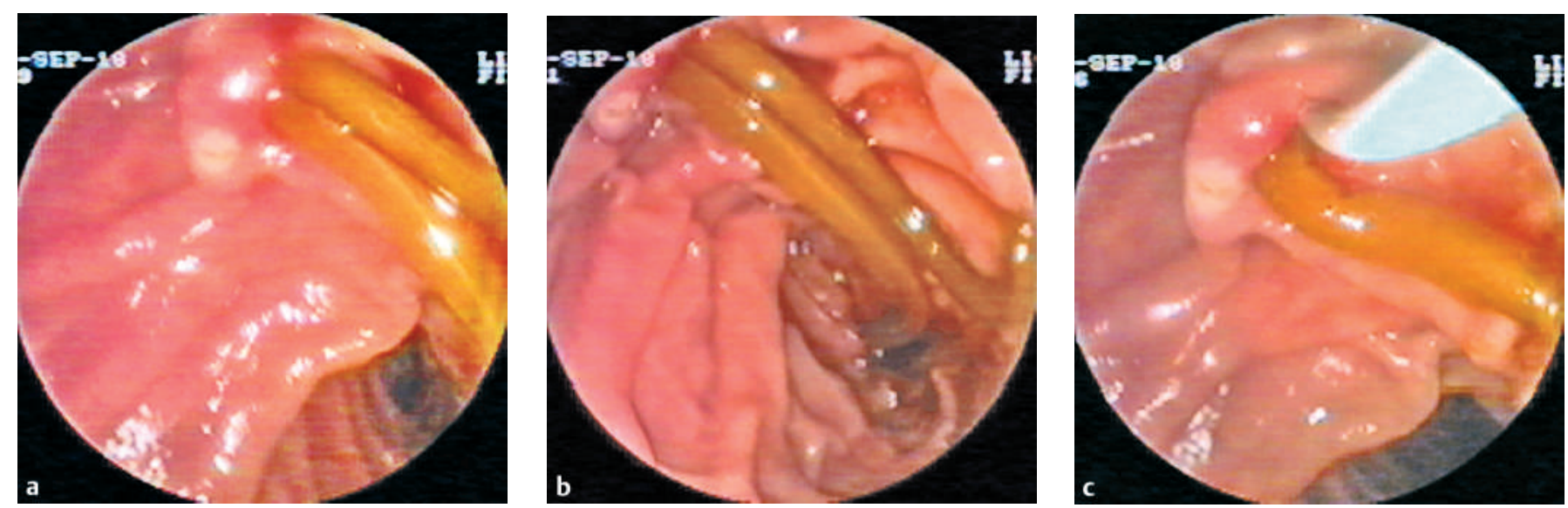

Figure $\mathbf{1} \mathbf{a}-\mathbf{c}$ The worm migrating out of the papilla.
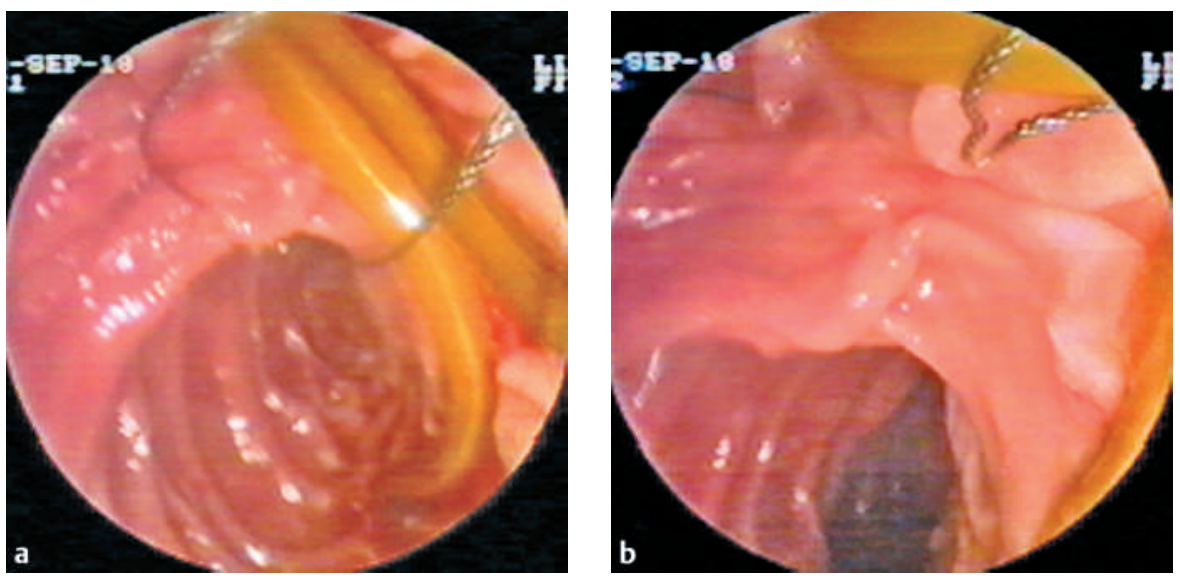

Figure $\mathbf{2}$ a, $\mathbf{b}$ The worm being removed with a polypectomy snare.

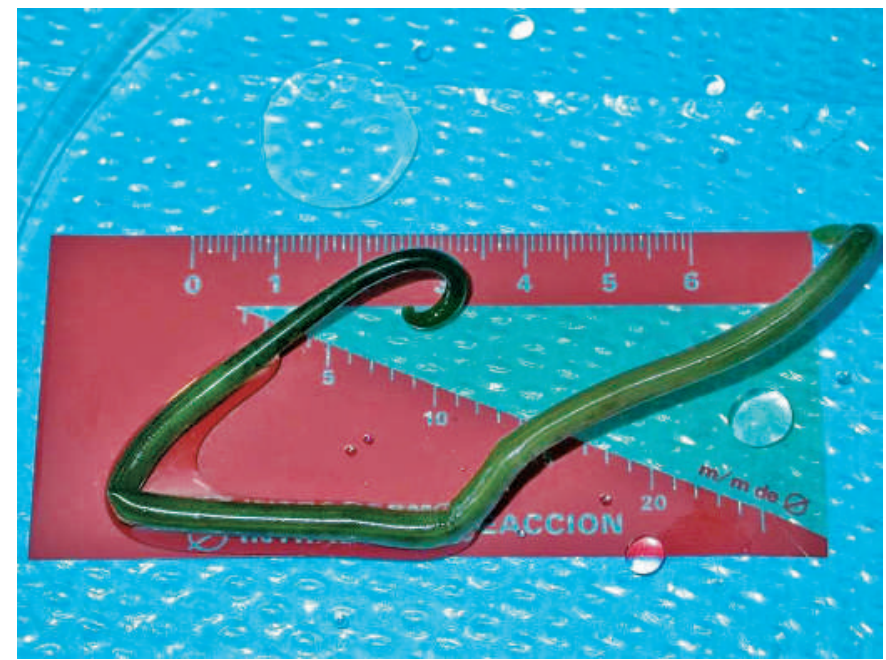

Figure 3 The adult form of Ascaris lumbricoides.

Parasitic infestations of the hepatic biliary tree most commonly involve Ascaris lumbricoides, which infects an estimated $25 \%$ of the world's population [1]. These infections are increasing in the developed countries due to world travel and popula- tion migrations. Individuals may be asymptomatic. When symptoms occur, they include pulmonary and hypersensitivity manifestations, and intestinal, hepatobiliary, and pancreatic symptoms [2]. Migration of adult worms into the biliary tree can cause abdominal pain, biliary colic, cholangitis, obstructive jaundice, strictures, hepatic abscesses, and pancreatitis. The diagnosis is made by identifying the egg or an adult worm in bile or feces, and it can be confirmed by ultrasonography or endoscopic retrograde cholangiopancreatography (ERCP). The typical ultrasound finding is linear, parallel echogenic structures with no acoustic shadowing, or non-shadowing echogenic strips with a central anechoic tube. ERCP is a highly sensitive method of demonstrating the worm in the biliary and pancreatic ducts [3]. When worms protrude out of the papilla, a grasping forceps can be used to hold them; when they are entirely within the bile duct, they can be stimulated to migrate out after contrast injection, or can be extracted using a basket or occlusion balloon. Patients should be treated with antihelminthic therapy to eradicate remaining worms [4].

We report here a case of a Colombian woman who presented with abdominal pain, suggesting cholecystitis and pancreatitis. Abdominal ultrasonography re-

DOI: $10.1055 / s-2006-944891$ 
vealed choledocholithiasis, and it was decided to carry out a therapeutic ERCP. With the patient under general anesthesia, a normal papilla was visualized with a side-viewing endoscope. A sphincterotomy was carried out, and a catheter was advanced through the ampulla. Contrast injection revealed a longitudinal and cylindrical filling defect. The worm then migrated out of the papilla (Figure $\mathbf{1}$ ), and it was removed with a polypectomy snare (Figure 2,3). Finally, the bile duct was cleared with physiological saline. Four months later, an ultrasound examination showed only aerobilia.
Endoscopy_UCTN_Code_CCL_1AZ_2AN

E. Zapata1, L. Zubiaurre' ${ }^{2}$, P. Salvador ${ }^{2}$, A. Castiella', L. F. Alzate' ${ }^{2}$, P. López ${ }^{2}$, J. A. Arriola², F. Múgika²

${ }^{1}$ Dept. of Gastroenterology and Hepatology, Mendaro Hospital, Mendaro, Basque Country, Spain

2 Dept. of Gastroenterology and Hepatology, Donostia Hospital, Basque Country Spain.

\section{References}

${ }^{1}$ Seltzer E. Ascariasis. In: Guerrant RL, Weller $\mathrm{PF}$, editors. Tropical infectious diseases: principles, pathogens and practice. Philadelphia: Churchill Livingstone, 1999: 553

2 Sandouk F, Haffar S, Zada MM et al. Pancreatic-biliary ascariasis: experience of 300 cases. Am J Gastroenterol 1997; 92: 2264 2267

${ }^{3}$ Al-Karawi M, Sanai FM, Yasawy MI, Mohammed AE. Biliary strictures and cholangitis secondary to ascariasis: endoscopic management. Gastrointest Endosc 1999; 50: 695-697

${ }^{4}$ Maipanich W, Pubampen S, Sa-nguankiat S et al. Effect of albendazole and mebendazole on soil-transmitted helminth eggs. Southeast Asian J Trop Med Public Health 1997; 28: $321-325$
Corresponding author

\section{E. Zapata, M.D.}

Dept. of Gastroenterology and Hepatology Mendaro Hospital

Mendaro

Guipuzcoa

Spain

Fax: $\quad+34-943032836$

Email: ezapata@hmen.osakidetza.net 